\title{
Dynamic digital human models for ergonomic analysis based on humanoid robotics techniques
}

\section{Giovanni De Magistris* and Alain Micaelli}

\author{
CEA, LIST, LSI, \\ rue de Noetzlin, \\ Gif-sur-Yvette, F-91190, France \\ E-mail: giovanni_demagistris@hotmail.it \\ E-mail: alain.micaelli@cea.fr \\ *Corresponding author
}

\section{Jonathan Savin, Clarisse Gaudez and Jacques Marsot}

Institut National de Recherche et de Sécurité (INRS), rue du Morvan, CS 60027, Vandoeuvre-lès-Nancy, F-54519, France

E-mail: jonathan.savin@inrs.fr

E-mail: clarisse.gaudez@inrs.fr

E-mail: jacques.marsot@inrs.fr

\begin{abstract}
Digital human models can be used for biomechanical risk factors assessment of a workstation and work activity design for which there is no physical equipment that can be tested using actual human postures and forces. Yet, using digital human model software packages is usually complex and time-consuming. A challenging aim therefore consists in developing an easy-to-use digital human model capable of computing dynamic, realistic movements and internal characteristics in quasi-real time, based on a simple description of future work tasks, in order to achieve reliable ergonomics assessments of various work task scenarios. We developed such a dynamic digital human model, which is automatically controlled in force and acceleration and inspired by human motor control and based on robotics and physics simulation. In our simulation framework, the digital human model motion was controlled by real-world Newtonian physical and mechanical laws. We also simulated and assessed experimental insert-fitting activities according to the occupational repetitive actions (OCRA) ergonomic index. Simulation led to satisfactory results: experimental and simulated ergonomics evaluations were consistent, and both joint torques and digital human model movements were realistic and coherent with human-like behaviours and performances.
\end{abstract}

Keywords: digital human model; DHM; human learning; dynamic control; ergonomic analysis

Reference to this paper should be made as follows: De Magistris, G., Micaelli, A., Savin, J., Gaudez, C. and Marsot, J. (2015) 'Dynamic digital human models for ergonomic analysis based on humanoid robotics techniques', Int. J. Digital Human, Vol. 1, No. 1, pp.81-109. 
Biographical notes: Giovanni De Magistris received his MS in Mechatronics Engineering from Politecnico di Torino, Italy, and from École Nationale Supérieure de Mécanique et des Microtechniques, Besançon, France. He received his $\mathrm{PhD}$ in Robotics and Mechanics in 2013 from the Universite Pierre et Marie Curie, Paris, France. He joined the Systems and Technologies Integration Laboratory, French Atomic Energy Commission in 2010. His current research interests include automatic control, whole-body control for virtual humans, and human behaviours.

Alain Micaelli received his degree in Engineering and $\mathrm{PhD}$ in Automatic Control and Signal Processing in 1979 and 1982, respectively, from the École Nationale Supérieure des Télécommunications, Paris, France, and from the University of Paris-Sud. He joined the French Atomic Energy Commission in 1982 and has been involved in several national and international projects dealing with teleoperation and mobile robotics. He is currently a Research Director in the field of automatic control. His research interests include the control of manipulators, telemanipulators, mobile robots, virtual reality, and, more specifically, virtual manikin.

Jonathan Savin graduated as engineer from the National Superior School of Physics (Telecom Physique, Strasbourg, France), and holds a Master in Mechanics and Engineering (with a biomechanics specialisation). After working for various companies as a Software Development Engineer, he joined the French Research and Safety Institute for the Prevention of Occupational Accidents and Diseases (INRS) as a project leader. His work focuses mainly on the integration of occupational risks during the initial design phases for work equipment, and specifically on assessing emerging design tools/techniques in this field (digital humans, virtual reality, and augmented reality).

Clarisse Gaudez is a Medical Doctor in charge of researches at INRS. She received her MD in 2001 from the University of Clermont Ferrand and $\mathrm{PhD}$ in Biomechanics in 2004 from the University of Paris VI. She also received her university degree in Applied Ergonomics in 1999. She joined INRS in 2004. Her research interests are related to the prevention of work related musculoskeletal disorders and to the prevention of occupational accidents induced by movement disturbance. Her work focuses on motor control, movement variability, gestures and strategies used by employees. She has conducted research protocol expertise from foreign counterparts of INRS and international journals.

Jacques Marsot graduated as engineer from ENIB (Belfort National School of Engineer). After ten years in the industry as designer and project leader, he joined in 1993 the French Research and Safety Institute for the Prevention of Occupational Accidents and Diseases (INRS). He is currently in charge of the Design Engineering of Safe Systems Laboratory. Activities of this laboratory focus for example on: ergonomic design of working equipment, drawing up methodologies to design safer machines, design of digital manikins or virtual environments to assess the potential strains related to working situations. 


\section{Introduction}

Digital human models (DHMs) can be used to improve workplace conditions that affect both worker safety and business success. The goal of this paper is to improve DHMs so that they can be used to help workstation designers to reliably identify and assess workplace induced musculoskeletal disorders (MSDs) and other biomechanical risks factors in the early stages of design.

Due to computer technology progress in the past 20 years, DHMs were developed for computer-aided design (CAD) software tools, in order to analyse workstation ergonomics (Claudon et al., 2006). Their diffusion has widely grown with the concept of the 'digital factory' (Arndt, 2006). Indeed, many CAD software tools now integrate DHMs, which allow designers, studies offices (Haesen, 2009) and consultants (Urbatic Concept France, 2007 ) to represent and virtually simulate operators in order to evaluate future workstation ergonomics (reach areas, physical performances, time analysis).

Today, DHMs which are used for design purposes are mentioned in different standards as potential tools for biomechanical risk factors assessment from the early stages of design (AFNOR, 2005, 2007). Used even before the achievement of a workstation physical prototype, DHMs thus contribute to the application of safety principles in the early stages of design, in conformity with European standards (European Union, 2006). Regarding this topic, there is abundant scientific literature about DHMs implementing ergonomics methods or industrial standards [for example, RULA (MacAtamney and Cortlett, 1993), OCRA (Occhipinti, 1998) and EAWS (Schaub et al., 2012)] for workstation ergonomics assessment in the early stages of design (Jayaram et al., 2006; Annarumma et al., 2008; Berlin et al., 2009). They may also play a positive role for communication and coordination between the different stakeholders of the project (designers, users, decision-makers, health and safety staff).

The use of DHMs hence makes sense for occupational risk prevention, for instance to reduce the risk of MSD occurrence, which represents a major proportion of declared occupational disorders (Sjogaard et al., 1995; Bernard, 1997). In 2011, MSDs in the USA represented a third of occupational disorders leading to leaves (Bureau of Labor Statistics, 2011); in France, it is the number one disorder compensated by social security, amounting to roughly $80 \%$ of recognised occupational disorders, and more than nine million lost workdays (CNAM-TS, 2012).

Actually, European designers must satisfy technical directive 2006/42/EC on machinery (European Union, 2006) and related harmonised standards. This directive deals with a priori risks assessment. By successive iterations, designers must obtain the lowest possible residual risks level (this is the integrated prevention concept) (AFNOR, 2010). Regarding the MSD issue, the directive requirements were intensified in the early 2010s: many standards related to physical risks assessment were added in the last five years, for instance NF EN 1005-5 (AFNOR, 2007) for MSD risks assessment related to high rate repetitive tasks. These standards are partly based on identification and counting of the operator's technical actions (conception data) and partly on assessments of biomechanical risks factors (postures, efforts, repetitive movements, task durations or other parameters).

In industry, one can find two classical ergonomic assessment modalities. The first is coarse, it is based on observations of the operator's activities through video recording and questionnaires, and it is used to qualitatively evaluate efforts and postures. The second is 
more precise, it requires advanced metrology means (force sensors or surface electromyography systems to quantitatively measure the operator's exertions; motion capture systems to measure the operator's joint positions). However, the second modality can hamper, and thus modify, the analysed task executions (since the operator is geared with sensors). Moreover, the second modality requires expert skills in biomechanics and physiology. In addition, both modalities cannot be used in the early design stages because they require prototypes of future workstations (Badler et al., 1993; Morrisey, 1998; Zhang et al., 2000). DHMs offer a complementary approach which relies on simulation. Although DHMs may cost more than the other two modalities in the early design stages of projects, they allow the examination of multiple design scenarios, even when physical mock-ups or prototypes are not available. As a result, they can rapidly lead to significant overall cost and development time reductions (Chaffin, 2001). When using DHMs, actual measurements using actual workstations are often eventually carried out to test final physical mock-ups or prototypes before the final products are produced and used.

The focus of our research then was to develop DHMs capable of performing simulated work tasks with dynamically consistent motions, behaviours and internal characteristics (positions, velocities, accelerations and torques) based on a simple description of future work-tasks, in order to achieve realistic ergonomics assessments of various work-task scenarios in the early stages of the design process. To obtain these goals, we developed dynamic DHMs which ware automatically controlled in force and acceleration (De Magistris et al., 2013a), and which were inspired by human motor control (Todorov and Jordan, 1998) and based on physics simulation. In our simulation framework, DHM motions were controlled by real-world Newtonian physical and mechanical laws and applied forces and torques were calculated by automatic control techniques. Our controller also handled multiple simultaneous tasks (balance, contacts, manipulations) in real time.

This paper consists of eight sections. The second and third sections describe existing DHMs and their limitations. The fourth section presents the advantages of our DHMs. The fifth section describes an application case which was used to experimentally validate our DHMs and also outlines the principles of our dynamic DHM controls. The sixth section describes outcomes, and, in particular, compares experimental and simulation results. Finally, the seventh and eighth sections present a discussion of the issues raised by the approach and its future prospects.

\section{A review of DHMs}

Around 1960, scientific literature presented the first DHMs. Initially, DHMs allowed graphical representation of a human in static conditions (for visualisation purposes users could primarily change the postures and anthropometric dimensions of the DHMs). Since then, dramatic improvements have been made, DHMs were first integrated into CAD software tools, and then have even been integrated into virtual reality systems (Chedmail et al., 2002). Today, designers can have their projects tested by future workers in complete 'scale 1' virtual environments. Now, various academic and industrial laboratories are still trying to enrich DHM functions and behaviours. For example, they are trying to upgrade them with advanced calculation units which can simulate realistic human-computer interactions (Pouliquen, 2006), and with real time joint effort 
calculations and optimisations of the operator's movements according to physical capabilities and actual risks present in the work environments (Shahrokhi and Bernard, 2009).

However, in this paper, we are primarily interested in the DHM tools which are used for workstation design. The main functions of such tools are:

1 The digital operator's representation in the $3 D$ CAD software tools. For this purpose, the DHMs can be feminine and masculine models which are characterised by anthropometrical or biomechanical factors (angular range of motion, maximum exertion, etc.), which are selected by the designers from anthropometrical or biomechanical databases.

2 Simulation of postures and/or activity sequences (gestures, posture changes, object prehensions, motions, etc.). In other words, the DHMs can be animated by either direct and/or inverse kinematic control, manually, from a database of predefined movements or by motion analysis systems.

3 Anthropometric prescriptions verification, collision detection and task execution time calculation. In other words, the operator's reach area and visual field are realistically and accurately included in the functionalities of the DHMs.

4 Biomechanical and/or physiological constraints assessment through the use of common ergonomic indices. Various ergonomic evaluators such as revised equations from NIOSH (1991), RULA methods (MacAtamney and Cortlett, 1993), OWAS (Karu et al., 1977), EAWS (http://inderscience.metapress.com/ content/m850j18564428m27/) and Snook tables (Liberty MutualTables, http://www.ccad.uiowa.edu/vsr/research/standard-ergonomicassesments/ liberty-mutual/) are used to evaluate the simulated tasks completed by the DHMs.

Table 1 sums up the main characteristics and functionalities of DHMs used by the main industrial or academic stakeholders in the CAD field. Table 1 shows that there are two groups of DHMs: on one hand those used in generic industrial contexts [for example, Jack (Badler, 1997), DELMIA (http://www.3ds.com/products-services/delmia), SAMMIE CAD (Porter et al., 2004) and ERGOMAN - PROCESS ENGINEER (Schaub et al., 1997)] and those specifically designed for a specific type of application (for example, RAMSIS (Seidl, 2004), BHMS (Rice, 2004), MAN3D (Monnier, 2004) and SantosHuman (VSR Research Group, 2004; Vignes, 2004)). Table 1 includes the DHMs' names and their producers. Columns three to ten stand for 'animation method' (AM); 'direct' (D) stands for direct kinematics; 'inverse' (I) stands for inverse kinematics; 'field of view' (FOV) stands for the extent of the observable world that is seen at any given moment by the DHM; 'reach area' (RA) stands for objects and the parts of the workstation that the DHM can reach; 'collision detection' (CD) stands for detection of contacts between two or more objects or between humans and objects; 'static effort' (SE) stands for human efforts in static conditions; 'ergonomic assessment indices' (EAI) stands for the types of workstation assessments; 'motion capture' (MC) stands for optional modules that can record the movements of objects or people; 'methods time measurement' (MTM) stands for calculation of standard times in which a worker can complete a task. 
Table 1 Main characteristics and functionalities of DHMs

\begin{tabular}{lccccccccc}
\hline Model & Society & AM & FOV & RA & CD & SE & EAI & $M C$ & $M T M$ \\
\hline Jack & Siemens PLM & D/I & Yes & Yes & Yes & Yes & NIOSH, & Yes & Yes \\
& Software & & & & & & $\begin{array}{c}\text { OWAS, } \\
\text { RULA }\end{array}$ & & \\
Delmia & Dassault Systèmes & D/I & Yes & Yes & Yes & Yes & RULA & No & No \\
ErgoMan & Dassault systèmes & D & Yes & Yes & No & Yes & NIOSH & No & Yes \\
Process & & & & & & & Snook tables & & \\
Enginee & & & & & & & & & \\
Ramsis & Human Solutions & D/I & Yes & Yes & Yes & Yes & No & No & No \\
SAMMIE CAD & SAMMIE CAD & D/I & Yes & Yes & Yes & No & NIOSH, & No & No \\
& Limited & & & & & RULA & & \\
BHMS & Boeing & D & Yes & Yes & Yes & No & No & No & No \\
MAN3D & IFSTTAR & D/I & Yes & Yes & Yes & Yes & No & Yes & No \\
SantosHuman & SantosHuman Inc. & D/I & No & Yes & Yes & Yes & NIOSH, & Yes & No \\
& & & & & & Snook tables & & \\
\hline
\end{tabular}

\section{DHM limitations}

When using DHMs, which are integrated to CAD software tools, during the early stages of design, one must consider various limitations, which are clearly described and identified in related literature:

1 HM posture set up is complex. It can be completely subjective when controlled by the designers, whether this task is carried out, in a direct way, by using a keyboard or, in an experimental way, by using a puppet (Yoshizaki et al., 2011). It can also rely on optimisation algorithms (Chaffin, 1997; Center for Ergonomics, 2004), computer techniques (Zhang et al., 2010), experimental data from motion capture devices (Wang, 2008; Fritzsche et al., 2011) or even the operating procedures given by process/method engineers (Kuo and Wang, 2009).

2 Most CAD DHMs only consider one or a few static postures, and thus they neglect constraints related to maintaining postures or balance (Lämkull et al., 2009), and therefore they cannot calculate complete movements, with acceleration and inertia effects.

3 DHM calculations for some ergonomic indices are not reliable, especially those that rely on relative exertions. In fact, when DHMs calculate such relative exertions, they compare physics-based simulated exertions to built-in maximal effort databases which are generally incomplete or approximate. The resulting errors in maximal exertions consequently lead to erroneous ergonomic indices (Savin, 2011). 
4 Interpretations of simulation results with DHMs require real ergonomic skills and substantial knowledge of MSD emergence mechanisms and related scientific fields (ergonomics, biomechanics, physiology, etc.) (Dukic et al., 2007). Actually, ergonomics processes require transverse cooperation between the different stakeholders (design, manufacturing, prevention) in a proactive ergonomic approach to design (Falck and Rosenqvist, 2012).

For these reasons, biomechanical risk factor assessment based upon DHM simulations can lead to underestimation: some studies report that up to $40 \%-50 \%$ of simulations classify risk lower than expected (Lämkull et al., 2009; Savin, 2011), which can lead to unsuitable design choices (Malchaire, 2011).

\section{Realistic simulation of human motion}

The aim of our work was to address some of the DHM limitations described in Section 3:

1 The aim of our work was to simplify and accelerate DHM simulation and animation processes. Our DHM allowed autonomous simulation motions (not only postures) given only minimum information about future work tasks.

2 The aim of our work was to give DHMs autonomous, objective and realistic behaviours from a global movement standpoint (postures, trajectories) as well to improve the data which is used to quantitatively define such behaviours (positions, velocities, accelerations, efforts, etc.), in order to calculate reliable ergonomic assessment indices: our DHM took account of dynamics, balance controls and contact forces, which were not considered by current DHMs in CAD software tools.

Precedent works (Colette et al., 2007, 2008; Mansour et al., 2011; Liu et al., 2011) showed that humanoid robotics techniques can be used to simulate autonomous motions. So we tried to create DHM control algorithms that were more objective and reliable than those of DHMs which were currently integrated into CAD software tools, by simultaneously considering both human behaviours and Newtonian mechanics laws.

\section{Development and validation processes}

Figure 1 presents our development and validation process for the dynamic DHM command laws, which were based on humanoid robotics techniques and inspired by human motor control laws. The process relied on one hand on the development of a simulation tool, and on the other hand on the validation of the tool by comparisons between experimental and simulated data and corresponding ergonomic evaluations. 
Figure 1 Development and validation process

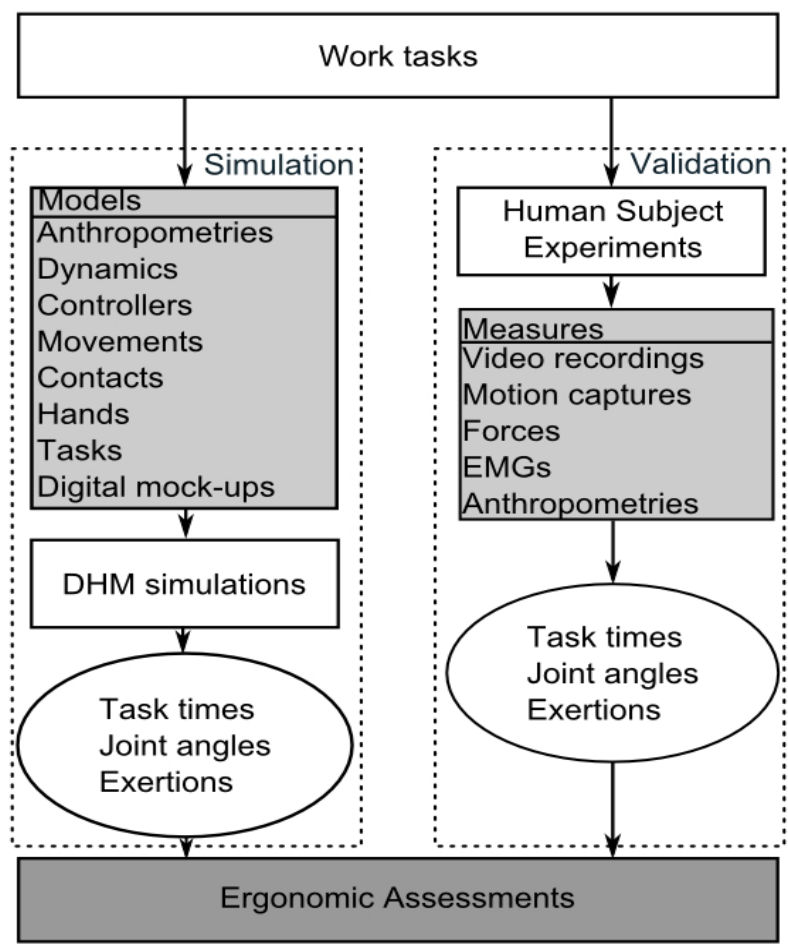

\subsection{Human subject experiments}

In the framework of our work, we chose to complete an experimental case-study. We chose to focus on repetitive manual assembly tasks, which can present significant MSD risks (Kilbom and Persson, 1987) when performed daily as main work activities. Assembly tasks being very diverse, we selected an activity of insert-fitting, which is a common work task, especially in the automobile or appliance industries. Moreover, the Laboratory for Biomechanics and Ergonomics (LBE) of Institut National de Recherche et de Sécurité (INRS) has previously studied this task, which consists of positioning and clamping metallic inserts on a plastic dashboard for a vehicle, both in a laboratory and in industrial settings (Gaudez, 2008).

The institutional ethics committee approved our experiments. Eleven healthy right-handed subjects (nine males and two females) took part in the case study [age $=29.4 \pm 9.2$ years (mean \pm standard deviation), height $=177.7 \pm 10.3 \mathrm{~cm}$, body mass $=75.9 \pm 9.3 \mathrm{~kg}$ ]. The subjects gave written consent before the experiments, and they filled out a health questionnaire. They already had some experience in insert-fitting throughout their careers. 
In De Magistris et al. (2013a), we described experiments which were conducted by agents of the INRS, which consisted of reproducing an insert-fitting workstation (see Figure 2). In this paper, we used data from the experiments as test data for our model validation process. Figure 2 shows experimental set-up for the human subjects experiments in this paper.

Figure 2 Human subject experiment (see online version for colours)
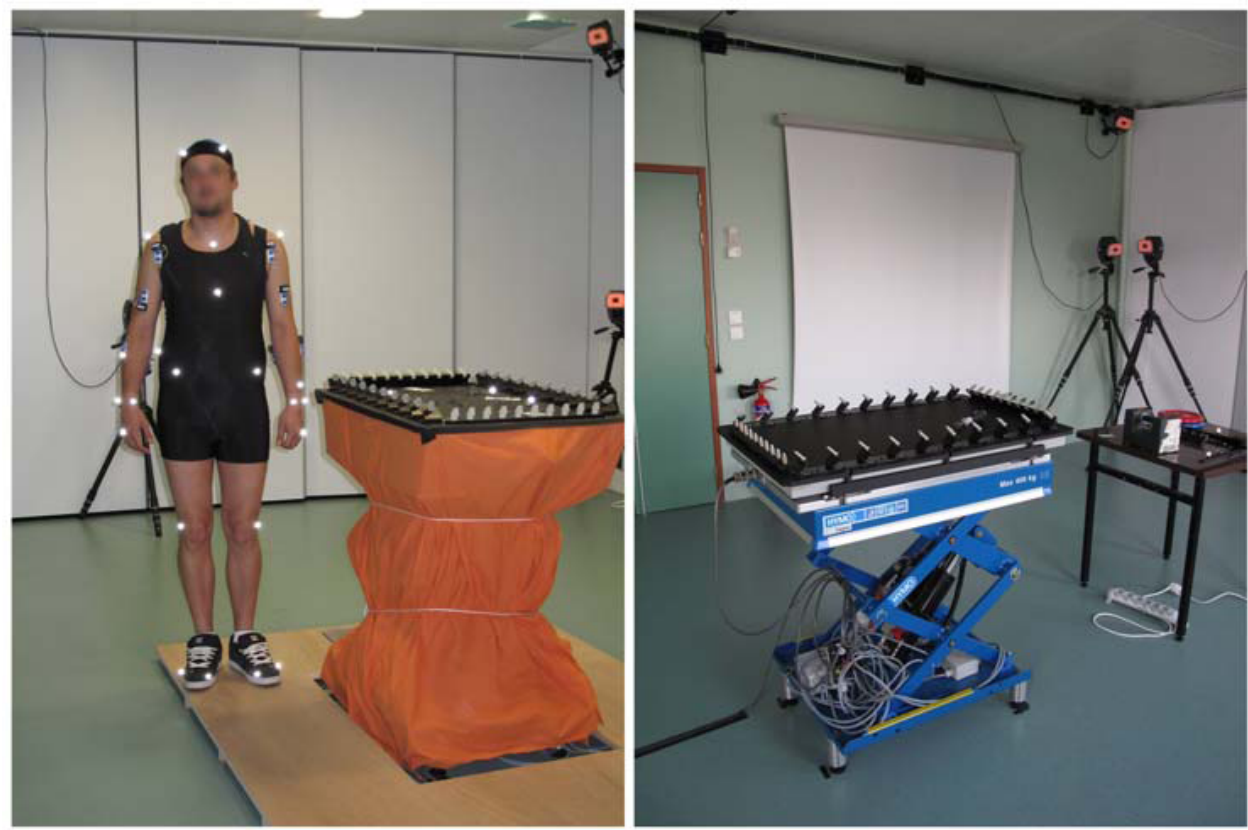

The subjects were asked to clip ten inserts [see Figure 3(a)] into related supports [see Figures 3(b) and 3(c)] using two methods: using only fingers or using a hand-held tool that meets specific ergonomic criteria (NST-n168, 1998) (see Figure 4).

Figure 3 Insert and support, (a) insert (b) support (c) insert placed on the support (see online version for colours)

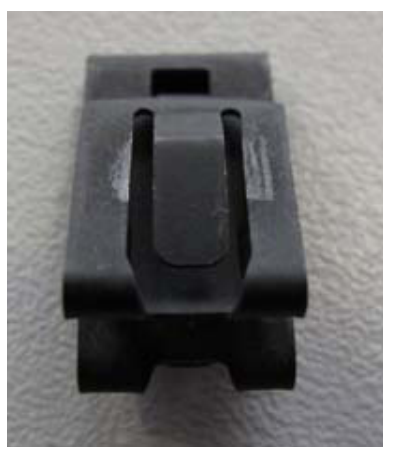

(a)

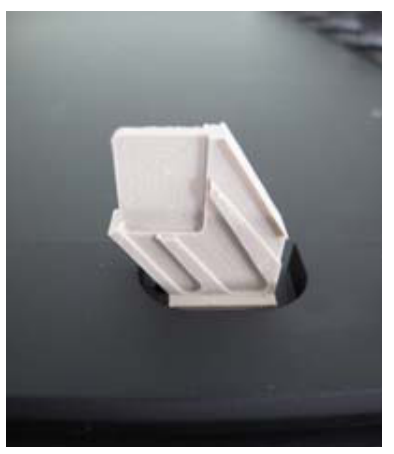

(b)

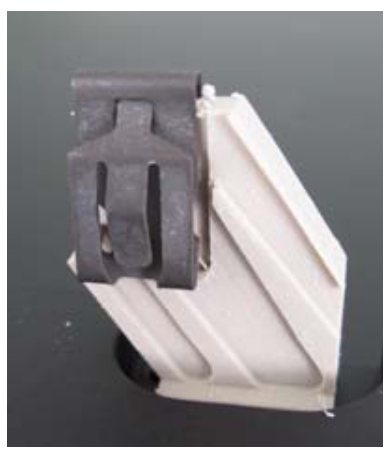

(c) 
Figure 4 Hand-held tool that meets specific ergonomic criteria (see online version for colours)

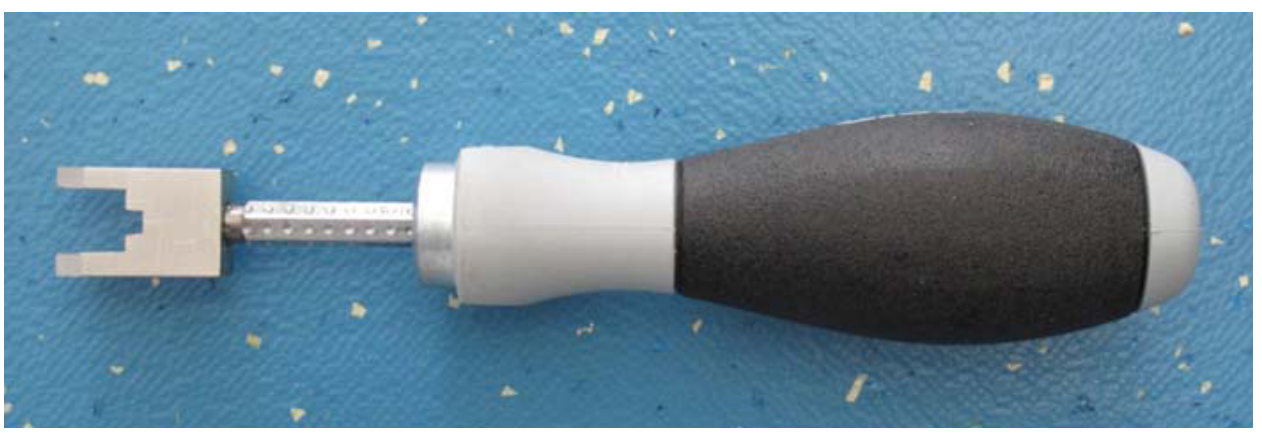

The subjects used four different strategies to fit the inserts using only fingers:

1 four subjects picked up the ten inserts one by one and clipped them onto the supports using only their right hands

2 four subjects picked up the ten inserts one by one from the table with their left hands, then transferred them to their right hands, which they then used to clip the inserts onto the supports

3 two subject picked up the ten inserts all at once from the table with their left hands, then picked up the inserts from their left hands with their right hands, which they then used to clip the inserts onto the supports

4 one subject picked up the inserts one by one from the table with their right hand, transferred them to their left hand to position them properly, then transferred them back to the right, which they then used to clip the inserts onto the supports.

For the remainder of this paper, we only analysed the first two strategies. The last two strategies were not analysed because the number of subjects was not sufficient for meaningful analysis.

When using the hand-held tool, all of the subjects used the same strategy: they all picked up the ten inserts one by one with their left hands and placed the inserts on the tool, which they held in their right hands. They then clipped the inserts onto the supports only using the tool.

\subsection{DHM simulation}

\subsubsection{Human body dynamics model}

In this paper, the DHM was divided in two separately articulated rigid body branches, which were used to model the human body and hands.

The human body was kinematically modelled as a set of articulated rigid bodies organised into a redundant tree structure (see Figure 5). The rigid bodies were characterised by their degrees of freedom (dof). Depending on the functions of the corresponding human segments, each articulation of the tree was modelled by a number of revolute joints. The human body was modelled and controlled at two separate levels, to reduce complexity: the first level was used to control the body, the second level was used to control the hands. The body model comprised 39 joint dof and 6 root dof, with 8 dof 
for each leg and 7 dof for each arm (see Figure 5). The root was not controlled. The dimensions were based on the subjects' anthropometries (Hanavan, 1964). Control of the body model is described in more detail later.

The DHM control is described later. The root was not controlled. The DHM dimensions were based on the subjects' anthropometries.

Figure 5 (a) Body model with skinning and collision geometry (b) Hand model with skinning and collision geometry (see online version for colours)

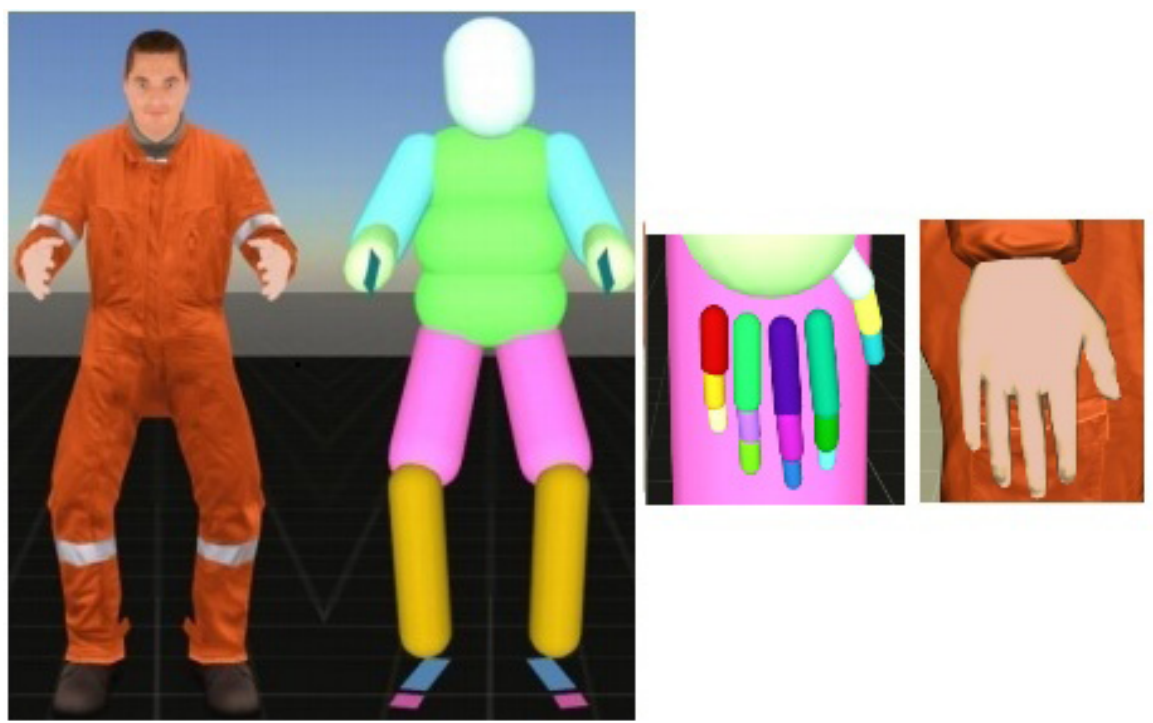

(a)

(b)

Each hand model had 20 dof (see Figure 5).We used a proportional-derivative controller to control joint position $\theta$ where a set of desired position $\theta_{d}$ corresponds to opened/closed hand and different preset grasps.

The dynamics model of a robot, which we used to control our DHM, was a second order system:

$$
M \dot{T}+N T+G^{r}=L \tau+\sum_{j} J_{c_{j}}^{T} W_{c_{j}}^{r}+\sum_{j} J_{e_{k}}^{T} W_{c_{k}}^{r}
$$

In equation (1), $M$ is the generalised inertia matrix, $N T$ stands for the centripetal and Coriolis forces, $\dot{T}$ and $T=\left[\operatorname{Vroot} \dot{q}_{1} \cdots \dot{q}_{n d o f}\right]^{t}$ are respectively the acceleration and velocity vectors in generalised coordinates, $G_{r}$ is the gravity force, $\tau=\left[\tau_{1} \cdots \tau_{\text {ndof }}\right]^{t}$ is the joint torque vector, $L=\left[0_{(n d o f, 6)} I_{n d o f}\right]^{t}$ is the matrix used to select the actuated dof, $W=[\Gamma F]^{t}$ denotes the external wrenches (see Figure 6) where $\Gamma$ is the moment and $F$ the force. The superscript $r$ denotes 'real' wrench values in a simulation. The subscript c stands for non-sliding contacts at known fixed locations such as the contacts between the feet and the ground. The subscript e stands for unknown contacts with the environment. 
Figure 6 DMU scenario with wrenches: com (centre of mass) for balance, head following end effector (EE) movement, thorax avoiding large movement, c (contacts) no sliding contacts, lhand (left hand) and rhand (right hand) end effectors for performing handling tasks (see online version for colours)

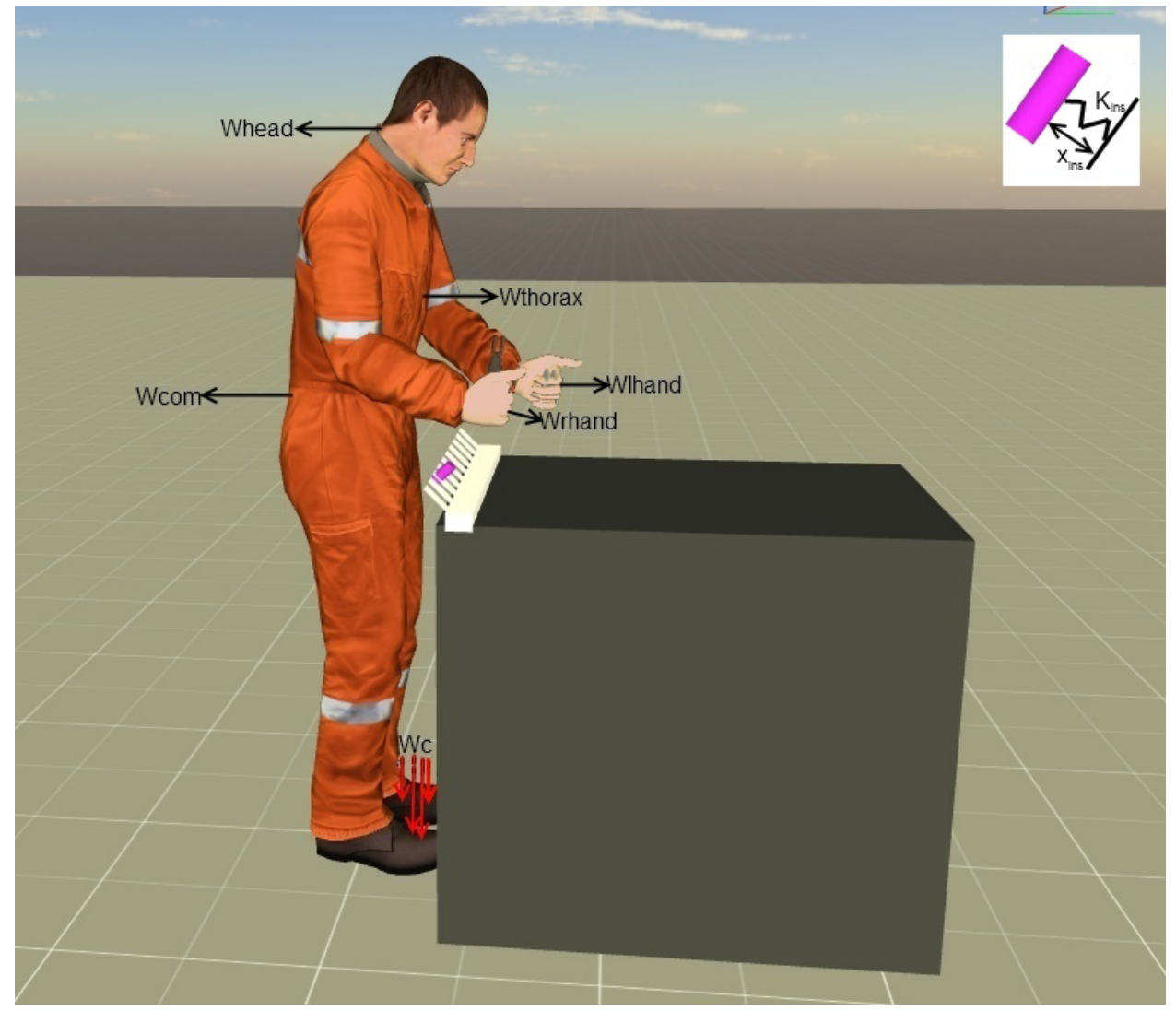

Note: The virtual object at the top right is a model of an insertion.

\subsubsection{Human-like dynamic DHM controls}

To control DHM movements and postures, we developed a multi-objective DHM controller. Common control techniques are based on pure stiffness compensation of internal and external disturbances. In this paper we used a controller which combined both feed-forward and feed-back techniques (De Magistris et al., 2013a), and which was inspired by human motor control principles. This is the novelty of our DHM, since precedent DHMs were generally based on kinematic control techniques.

In addition, when a multi-body system contacts another object, it is important to make the limbs more compliant to avoid 'contact instabilities' (Hogan, 1990). Therefore, we also noted that feed-forward control was also needed to properly control DHMs as mechanical systems. A number of studies have shown that the nervous system uses internal representations to anticipate the consequences of dynamic interaction forces. In particular, Lackner and Dizio (1994) demonstrated that the central nervous system (CNS) is able to predict centripetal and Coriolis forces; Gribble and Ostry (1999) demonstrated 
compensation of interaction torques during multijoint limb movements. These studies suggested that the nervous system has sophisticated anticipatory capabilities. We therefore also developed an accurate internal representation or an inverse model which we used to control body dynamics in object-filled environments.

Based on the notion underlying the acceleration-based control method (Abe et al., 2007; Colette et al., 2008) and the Jacobian-Transpose (JT) control method (Pratt et al., 1996; Liu et al., 2011; De Magistris et al., 2011, 2013b), we developed a combined anticipatory feed-forward and feed-back control system. This controller was formulated as two successive quadratic programming (QP) problems with multiple dof which were used to simultaneously solve all the constraint equations. The first QP problem was the feedforward control and the second QP problem was the feed-back control. This computational optimisation framework was first described in De Magistris et al. (2013a, 2014).

To simulate the tasks described in De Magistris et al. (2013a), several objectives were identified and prioritised:

1 Centre of mass (com). The dynamic controller maintained the DHM's balance by imposing that the horizontal plane projection of the centre of mass (com) lied within a convex support region (Bretl and Lall, 2008).

2 Thorax. We observed that the subjects' thorax orientation varied very little, during the experimental tasks. We therefore controlled the DHM's thorax orientation to stay as close as possible to its initial orientation.

3 Posture. We specified one of the DHM's joint positions as a reference position for the entire simulation, to obtain more realistic movements, and to avoid any singularities.

4 End effectors (EE). This feature performed the specific manipulation tasks.

5 Head. During the experimental tasks, we observed that the head followed the movements of the end effector performing the predominant manipulation task. We therefore specified this as our head objective.

6 Contact force. We set the contact force to zero for a regularisation of the QP problem.

7 Gravity compensation. We included a gravity compensation objective to make the target tracking control independent of gravity compensation.

\subsubsection{Human-like movements}

The DHM's movements were characterised by the initial and final points of the trajectories (positions and orientations) and their durations. We also included imposed way-points in order to avoid potential obstacles (for instance a table edge) because the DHM's controller did not include collision avoidance.

For the calculation of desired trajectories and velocities, we took into account experimental studies of human movements found in literature. Previous papers showed that voluntary movements obey the following three major psycho-physical principles: 
- Hick-Hyman's Law: the average reaction time $T_{R_{a v e}}$ of a real human depends on the logarithm of the $n$ probable choices (Hyman, 1953):

$$
T_{R_{\text {ave }}}=d \log _{2}(n+1)
$$

- Fitts'Law: the movement times of a real human depend on the logarithms of the relative accuracies (the ratios between movement amplitudes and target dimensions) (Fitts, 1954):

$$
D=g+z \log _{2}(2 \Upsilon P)
$$

where $D$ is duration time, $\Upsilon$ is amplitude, $P$ is accuracy, $g$ and $z$ are empirically determined constants.

- Kinematics invariance: the hand movements of a real human have a bell-shaped speed profile in straight reaching movements (Morasso, 1981). For more complex trajectories (i.e., handwriting) a $2 / 3$ power law can be used to predict the correlation between movement speed and trajectory curvature (Morasso and Mussa-Ivaldi, 1982) described as:

$$
s(t)=Z_{s} R^{1-\frac{2}{3}}
$$

where $s^{\cdot}(t)$ is tangential velocity, $R$ is radius of curvature and $Z_{s}$ is a proportionality constant, also called 'velocity gain factor'.

For a real human, more complex trajectories can be divided into overlapping basic trajectories similar to reaching movements. Such spatio-temporal invariant features of normal movements can be explained by a variety of criteria related to maximum smoothness, such as the minimum jerk criterion (Flash and Hogan, 1985) or the minimum torque-change criterion (Uno et al., 1989). As a result, for the DHM, we implemented a modified minimum jerk criterion with via-points, which were used to calculate trajectories. The methods which we used were first presented in De Magistris et al. (2013a), and they were originally inspired by the work of Todorov and Jordan (1998). In order to calculate trajectories for both rotations and translations, we only needed to find start, intermediates and end points $X$, start and end velocities $V$ and start and end accelerations $A$. Intermediate times $T_{P}$ were found using a nonlinear simplex method, which minimised jerk over all possible passage times.

\subsubsection{Contacts}

The simulations were completed using the XDE-Core physics simulation module developed by CEA-LIST. The simulation module managed the entire simulation in real time, including collision resolution, contact constraints and friction effects, which were modelled in compliance with Coulomb's friction law:

$$
\left\|f_{x y}\right\| \leq \mu\left\|f_{z}\right\|
$$

where $\left\|f_{x y}\right\|$ is a tangential contact force, $\mu$ is a dry friction factor and $\left\|f_{z}\right\|$ is a normal contact force. 
The central component of the XDE-Core physical engine was a generalised virtual mechanism (GVM) mechanical calculation module. The GVM module was used to manage multi-body systems and rigid or deformable contacts, and its mechanical formalisms were based upon Lie's groups (Merlhiot, 2009). It also used interactive and real-time algorithms.

The XDE-Core physical engine also included a component which detected multiple impacts. The module used a discrete local minimum distance (LMD) algorithm, which did not need to calculate the global distances between objects. The module could detect multiple impacts by only calculating the local minimum distances between one or two points on the surfaces of each of the objects. If one of these distances was zero, the module assumed there was an impact. The module also dilated the meshes used to represent objects, which rounded off edges, and gave the module the ability to tolerate minor defects in the meshes.

Previous related papers have verified that performance of the XDE-Core physical engine is good, when used in simulation contexts, for DHMs in virtual reality environments (Mansour et al., 2011; Liu et al., 2011).

\subsubsection{Digital mock-up}

The digital mock-up (DMU) scenario (see Figure 6) reproduced the experimental environment and ensured geometric similarity. The inputs used to build the DMU scenario were the workplace spatial organisation ( $\mathrm{x}, \mathrm{y}$ and $\mathrm{z}$ dimensions), inserts and tool descriptions ( $\mathrm{x}, \mathrm{y}, \mathrm{z}$ positions and weights) and the initial DHM position. The virtual object at the top right of Figure 6 is a model of an insertion with force $F_{\text {ins }}=K_{\text {ins }} \cdot x_{\text {ins }}=60 \mathrm{~N}$.

\subsubsection{Task models}

To model an insert-fitting task, we proceeded just like work situation designers in design or methods offices: the task was divided into motion sequences or elementary postures. For a simulation, the insert-fitting task was modelled with the finite state machine (FSM) in Figure 7. The FSM used terminology come from conception methods [for example, MTM - methods time measurement (Maynard et al., 1948)] or ergonomic evaluations [for example, OCRA - occupational repetitive actions (Occhipinti, 1998)].

In Figure 7, the states for the one-handed (right hand) insert fitting task were:

1 WAIT: At the beginning of the insert-fitting task, the DHM's body was in a vertical position, with its arms resting on its sides.

2 REACH: The DHM's hand took a prehension position and reached for an insert. The DHM's eyes followed the motion of the DHM's right hand.

3 GRASP: The subject closed the fingers of the right hand and took the insert.

4 POSITION: The DHM's right hand moved toward an insertion point. The DHM's eyes followed the DHM's right hand.

5 PLACE: The DHM fitted the insert into a vacant support.

6 RELEASE: The DHM's fingers on its right hand opened. 
7 REACH: The DHM's body returned to its initial position.

8 WAIT: At the end of an insert-fitting task, the DHM waited in its initial position. The DHM's body was in vertical position, with its arms resting on its sides.

Figure 7 also shows the states for the two-handed (right hand and left hand) insert fitting task.

Figure 7 The states for an insertion task (one-handed at the top; two-handed at the bottom)
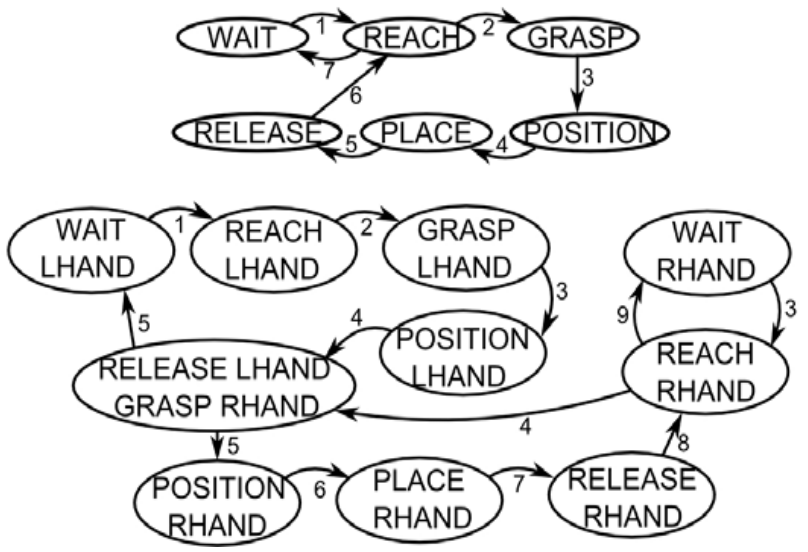

The states for the insert fitting task with a tool were the same as the states for the two-handed insert fitting task, except the RELEASE LHAND and GRASP RHAND states were replaced by a PLACE LHAND state, because the DHM placed an insert on the tool with its left hand.

\section{Results}

To obtain the results presented in this section, we implemented our DHM on a PC (12 M Cache, $2.53 \mathrm{GHz}$ Processor, $24 \mathrm{~GB}$ of RAM).

With a simulation step of $0.01 \mathrm{~s}$, the joint torques were calculated in quasi-real-time (the computation durations were 1.5 times the simulation duration).

\subsection{Trajectories}

To compare trajectories from real human experiments $X^{h}$ and from simulations $X^{s}$, we analysed the trajectories of the 'POSITION' steps of the finite state machines for four subjects. We chose to compare six experimental medial clip insertion trajectories to six simulated trajectories. We did not compare trajectories for the first and last two clips.

The experimental trajectories and the simulated trajectories had different start and end points, and they had different duration times. For this reason, we needed to apply a set of elementary affine transformations to compare these trajectories. 


\subsubsection{Spatial transformations}

1 Translation. The first step of the spatial transformations consisted of matching experimental and simulated start points. The first step was used to translate the trajectories to their start points:

$$
X^{s}=\left(\begin{array}{c}
x^{s}(t)-x^{s}(0) \\
y^{s}(t)-y^{s}(0) \\
z^{s}(t)-z^{s}(0)
\end{array}\right), \quad X^{h}=\left(\begin{array}{l}
x^{h}(t)-x^{h}(0) \\
y^{h}(t)-y^{h}(0) \\
z^{h}(t)-z^{h}(0)
\end{array}\right)
$$

where time $t \in\left[0, \ldots, t_{f}\right]$.

2 Rotation between vectors. The second step of the spatial transformations consisted of a rotation. The second step was used to rotate the experimental trajectory to match the simulated trajectory, by calculating the cross product and the angle between the experimental trajectory and the simulated trajectory: $X^{s}\left(t_{f}\right)=\left[x_{f}^{s} y_{f}^{s} z_{f}^{s}\right]$ and $X^{h}\left(t_{f}\right)=\left[x_{f}^{h} y_{f}^{h} z_{f}^{h}\right]$.

The cross product was calculated by calculating the determinant of a formal matrix:

$$
\mathbf{X}^{\mathbf{s}}\left(t_{f}\right) \times \mathbf{X}^{\mathbf{h}}\left(t_{f}\right)=\left[\begin{array}{lll}
\mathbf{i} & \mathbf{j} & \mathbf{k} \\
x_{f}^{s} & y_{f}^{s} z_{f}^{s} \\
x_{f}^{h} & y_{f}^{h} z_{f}^{h}
\end{array}\right]
$$

Using Sarrus' rule, the cross product was expanded to:

$$
\begin{aligned}
\mathbf{X}^{\mathbf{s}}\left(t_{f}\right) \times \mathbf{X}^{\mathbf{h}}\left(t_{f}\right) & =\mathbf{i}\left(y_{f}^{s} z_{f}^{h}-z_{f}^{s} y_{f}^{h}\right)+\mathbf{j}\left(z_{f}^{s} x_{f}^{h}-x_{f}^{s} z_{f}^{h}\right)+\mathbf{k}\left(x_{f}^{s} y_{f}^{h}-y_{f}^{s} x_{f}^{h}\right) \\
& =\mathbf{i} u_{x}+\mathbf{j} u_{y}+\mathbf{k} u_{z}
\end{aligned}
$$

where $u_{x}=\left(y_{f}^{s} z_{f}^{h}-z_{f}^{s} y_{f}^{h}\right), u_{y}=\left(z_{f}^{s} x_{f}^{h}-x_{f}^{s} z_{f}^{h}\right)$ and $u_{y}=\left(x_{f}^{s} y_{f}^{h}-y_{f}^{s} x_{f}^{h}\right)$ are the components of the unit vector $\mathbf{u}=\left(u_{x}, u_{y}, u_{z}\right)$.

The angle between the trajectories vectors was calculated by calculating the arccosine of the scalar product of the trajectories:

$$
\theta=\arccos \left(\mathbf{X}^{\mathbf{s}}\left(t_{f}\right) \cdot \mathbf{X}^{\mathbf{h}}\left(t_{f}\right)\right)
$$

3 Homothetic transformation. The third step of the scalar transformations was used to match the positions in the experimental trajectory and the simulated trajectory. A homothetic transformation, with scale factor $\lambda$ was used to match the positions:

$$
\lambda=\frac{\left\|X^{s}\left(t_{f}\right)\right\|}{\left\|X^{h}\left(t_{f}\right)\right\|}
$$


4 Rotation to obtain coplanarity of three key-points. The fourth step of the scalar transformations was used to obtain coplanarity of three key-points in the experimental and simulated trajectories. The calculated the vector $\mathbf{C}=\left(C_{x}, C_{y}, C_{z}\right)$ of the segment $\overrightarrow{O X^{h}}$ defined by the start and end points of each trajectory, and a rotation about $\overrightarrow{O X^{h}}$ was used to obtain coplanarity (see Figure 8).

Figure 8 Rotation to obtain coplanarity of three key-points

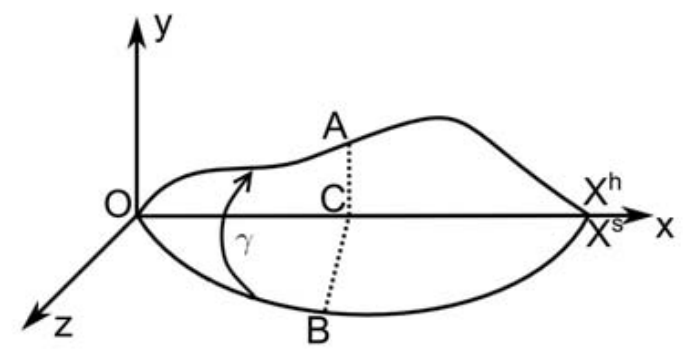

To obtain coplanarity of the trajectories $X^{h}$ and $X^{s}$, we rotated by $\gamma$ the simulated trajectory onto the experimental trajectory:

$$
\gamma=\arccos \left(\frac{\overrightarrow{A C} \cdot \overrightarrow{B C}}{\|\overrightarrow{A C}\|\|\overrightarrow{B C}\|}\right)
$$

where $\mathbf{A}$ and $\mathbf{B}$ are respectively the projections of $\mathbf{C}$ onto $X^{h}$ and $X^{s}$.

\subsubsection{Distances between trajectories}

Various methods from previous literature can be used to calculate the distances between two trajectories, which are defined by two non-empty point sets. One common method consists of calculating the Hausdorff distance between the two sets of points.

This method can be used to measure the 'closeness' of two non-empty point sets which are subsets of a metric space. The method assigns a scalar score or distance to the two trajectories, which measures the similarity between the two trajectories (Chen et al., 2011). This distance is defined as:

$$
d_{\mathrm{H}}\left(\mathbf{X}^{\mathbf{h}}, \mathbf{X}^{\mathbf{s}}\right)=\max \left\{\sup _{x \in \mathbf{X}^{\mathbf{h}}} \inf _{y \in \mathbf{X}^{\mathbf{s}}} d(x, y), \sup _{y \in \mathbf{X}^{\mathbf{s}}} \inf _{x \in \mathbf{X}^{\mathbf{h}}} d(x, y)\right\}
$$

where sup is supremum and inf is infimum.

The results in this section present both the Hausdorff distances and the average distances between the experimental trajectories and the simulated trajectories. The average distances were calculated using the following definition:

$$
d_{\text {ave }}\left(\mathbf{X}^{\mathbf{h}}, \mathbf{X}^{\mathbf{s}}\right)=\operatorname{mean}_{x \in \mathbf{X}^{\mathbf{h}}} \inf _{y \in \mathbf{X}^{\mathbf{s}}} d(x, y)
$$




\subsubsection{Results}

Table 2 shows the distances between the experimental trajectories and the simulated trajectories, for the four experimental subjects, at the 'POSITION' steps of the finite state machines (see Figure 7). The distances are given for the six central one-handed insertion tasks. Figure 9, compares the experimental trajectories and the simulated trajectories, for all subjects, and for all of the right-handed insertion tasks.

Table 2 Right wrist trajectories - distances between trajectories for all insertions

\begin{tabular}{lcc}
\hline Subject & Hausdorff distance & Average distance \\
\hline 1 & $(1.1 \pm 0.3) \mathrm{cm}$ & $(0.5 \pm 0.1) \mathrm{cm}$ \\
2 & $(1.5 \pm 0.4) \mathrm{cm}$ & $(0.7 \pm 0.2) \mathrm{cm}$ \\
3 & $(1.7 \pm 0.5) \mathrm{cm}$ & $(0.9 \pm 0.3) \mathrm{cm}$ \\
4 & $(2.6 \pm 1.2) \mathrm{cm}$ & $(1.5 \pm 0.6) \mathrm{cm}$ \\
\hline
\end{tabular}

Figure 9 Right wrist trajectories for all subjects (see online version for colours)
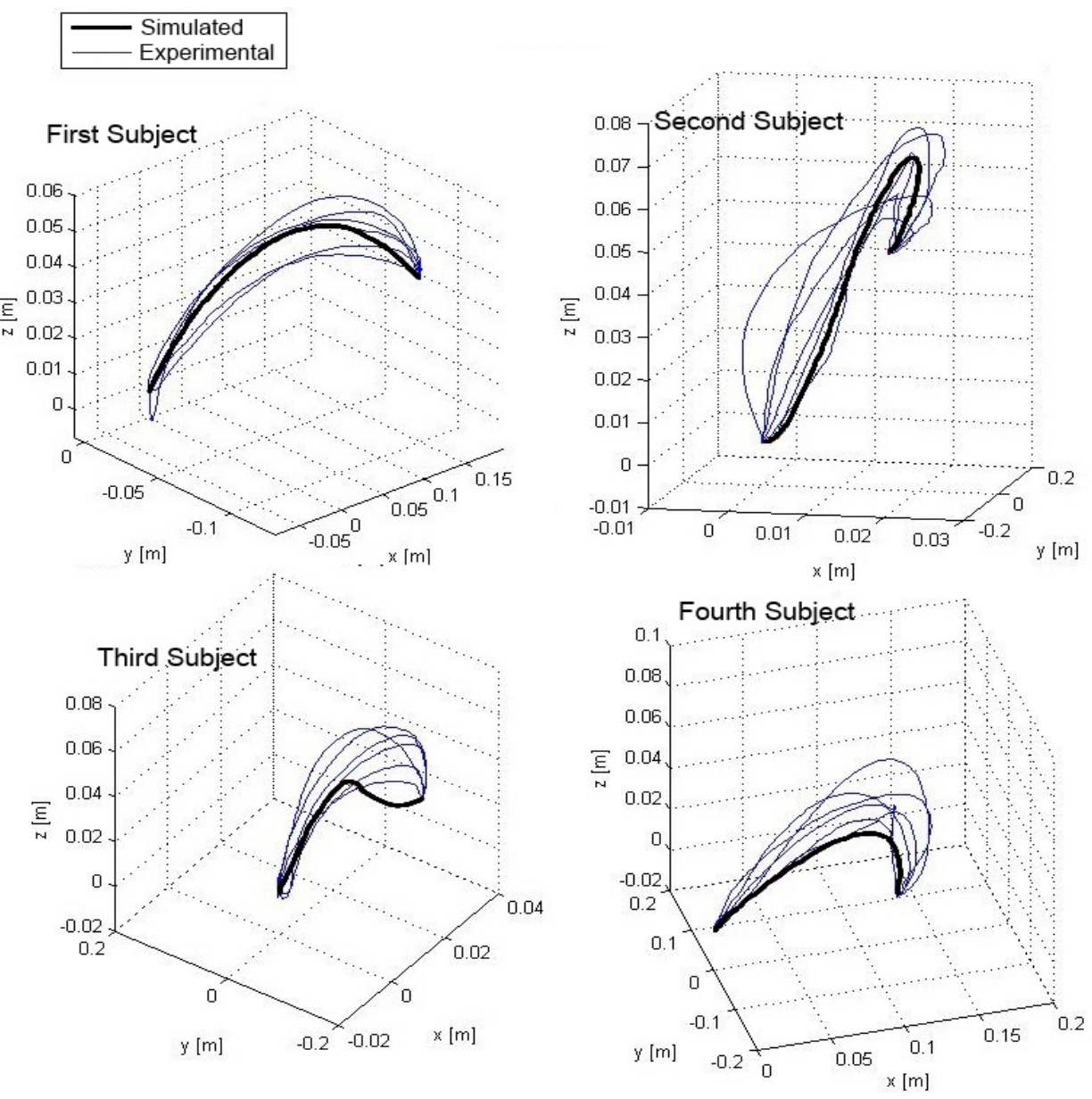


\subsection{Velocities}

To compare the trajectories, which were completed with different velocities, dimensionless normalised time was used:

$$
\bar{t}=\frac{t}{t_{f}}
$$

where $t_{f}$ is the duration of the rigid body motion. Multiplying $V(t)$ by $t_{f}$ and substituting $t$ by $\bar{t}$, makes the velocities independent of the time scale (Schutter, 2010).

Figure 10 shows the resulting velocities for the experimental trajectories and the simulated trajectories, at the 'POSITION' step of the finite state machines (see Figure 7), for the four subjects, and the right-handed insertion tasks.

Figure 10 Right wrist velocities for all subjects (see online version for colours)
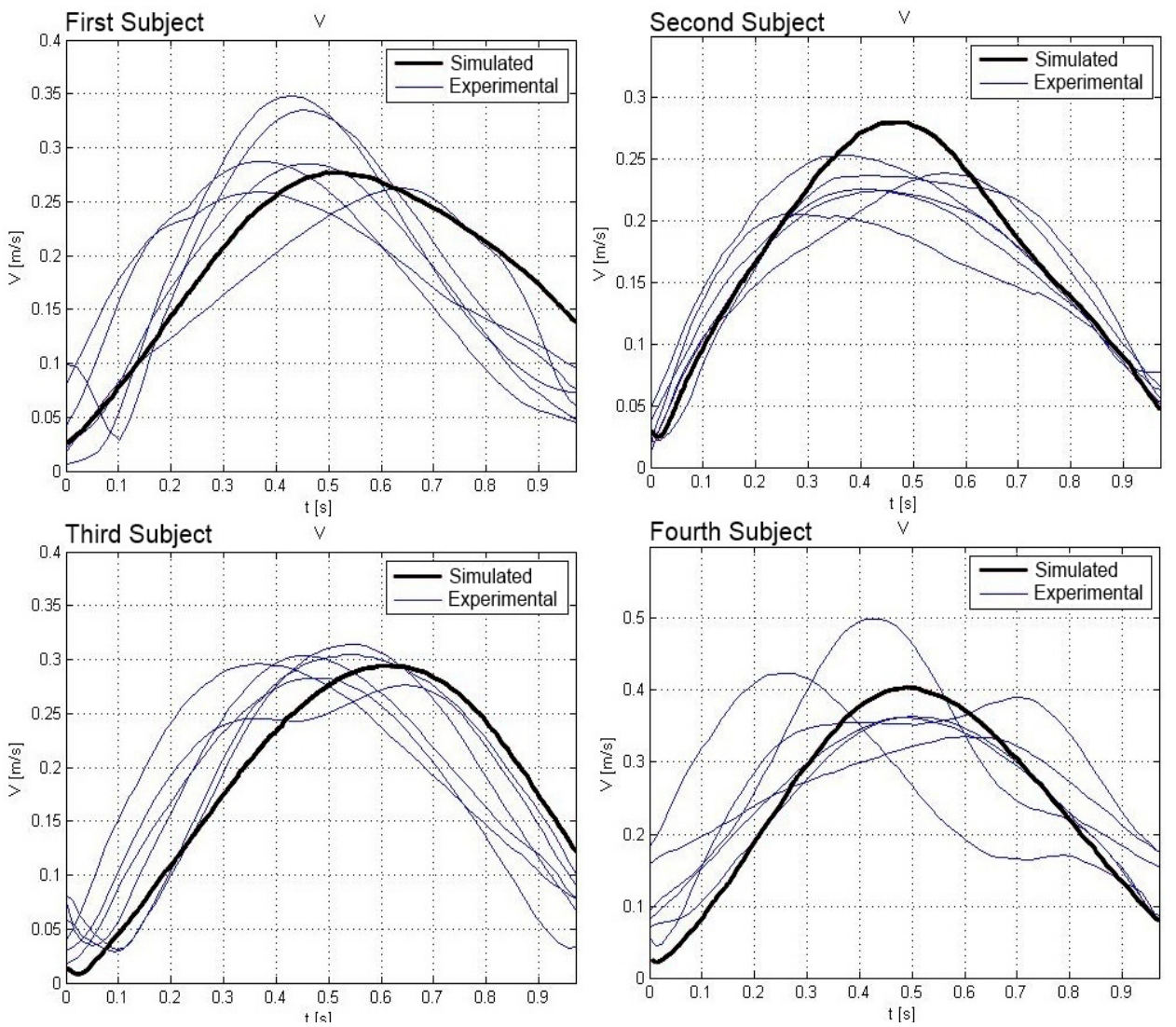

\subsection{Torque analysis}

The torques calculated during the simulations were suitable for human performance capabilities. For example, the maximum simulated value of the right elbow flexion torque was about $22 \mathrm{~N} \cdot \mathrm{m}$ and $5 \mathrm{~N} \cdot \mathrm{m}$ for the wrist torque (see Figure 11). The torque values 
calculated during the simulations were always smaller than maximum admissible torques at the elbow and wrist joints (the maximum torques at the elbow are approximately $70 \mathrm{~N}$ $\cdot \mathrm{m}$ for men and $35 \mathrm{~N} \cdot \mathrm{m}$ for women (Askew et al., 1981) and approximately $8.05 \mathrm{~N} \cdot \mathrm{m}$ for flexion at the wrist and $6.53 \mathrm{~N} \cdot \mathrm{m}$ for extension at the wrist for both men and women (Ciriello et al., 2001).

Figure 11 Simulated torques, (a) right elbow torque (b) right wrist torque (see online version for colours)

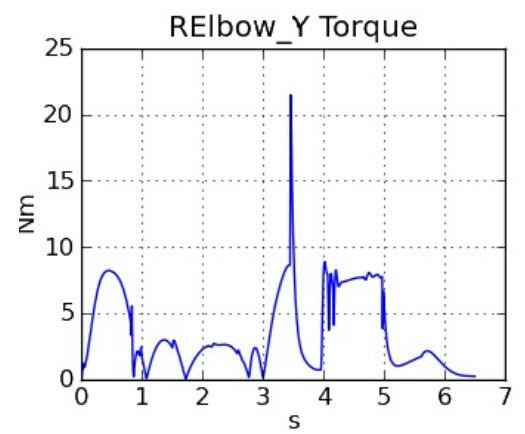

(a)

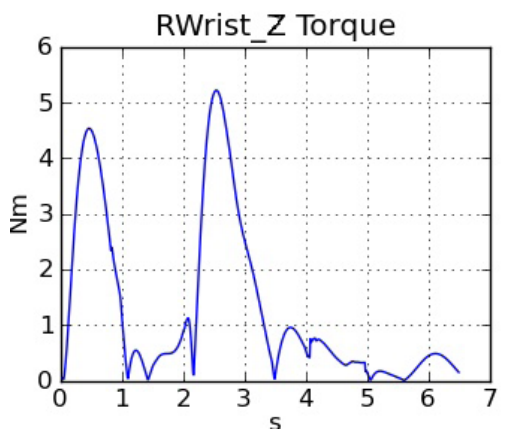

(b)

\subsection{Ergonomic assessment}

The OCRA ergonomic index was used to evaluate both the experimental insertion tasks and the simulated insertion tasks (Occhipinti, 1998; European Union, 2006). Tables 3 to 5 show the OCRA assessments.

The OCRA index is the ratio between the total number of observed technical actions (ATA) and the total number of recommended technical actions (RTA) (for each upper limb):

$$
\begin{aligned}
& \text { OCRA }=\frac{\text { ATA }}{\text { RTA }} \\
& \text { ATA }=\text { F } \cdot \mathrm{D}=\frac{\mathrm{NTC} \cdot 60}{\mathrm{CT} \cdot \mathrm{D}}
\end{aligned}
$$

where F is the frequency per minute; NTC is the number of technical actions in a cycle; $\mathrm{CT}$ is the cycle time in seconds; D is the evaluated net duration of the repetitive task during the work shift in minutes, and

$$
\mathrm{RTA}=\mathrm{CF} \cdot \mathrm{PoM} \cdot \mathrm{ReM} \cdot \mathrm{AdM} \cdot \mathrm{FoM} \cdot(\mathrm{RcM} \cdot \mathrm{DuM})
$$

where $\mathrm{CF}$ is a frequency constant related to the number of technical actions per minute, in this paper (30 actions per minute); PoM, ReM, FoM are multiplier factors, with values which range between 0 and 1 , and which are selected according to the characteristics of the posture (PoM), repetitiveness (ReM) and force (FoM); AdM are risk factors for additional elements; DuM is a duration multiplier and RcM is selected based upon ability to recover. 
Table 3 OCRA index values for the one-handed insertion task

\begin{tabular}{|c|c|c|}
\hline & Human subject experiment & $D H M s$ \\
\hline & $R U L$ & $R U L$ \\
\hline NTC & 3 & 3 \\
\hline $\mathrm{CT}$ & $3.89 \pm 0.41$ & $4.07 \pm 0.43$ \\
\hline $\mathrm{F}$ & $46.71 \pm 4.87$ & $44.67 \pm 4.72$ \\
\hline $\mathrm{D}$ & $0.39 \pm 0.04$ & $0.41 \pm 0.04$ \\
\hline$A T A$ & 18 & 18 \\
\hline $\mathrm{CF}$ & 30 & 30 \\
\hline FoM & $0.64 \pm 0.19$ & $0.64 \pm 0.19$ \\
\hline PoM & $0.55 \pm 0.08$ & $0.52 \pm 0.04$ \\
\hline ReM & 0.7 & 0.7 \\
\hline AdM & 1 & 1 \\
\hline$R P A$ & $2.93 \pm 1.20$ & $2.83 \pm 0.85$ \\
\hline DuM & 1 & 1 \\
\hline RcM & 1 & 1 \\
\hline$R T A$ & $2.93 \pm 1.20$ & $2.83 \pm 0.85$ \\
\hline OCRA & $7.25 \pm 3.70$ & $7.19 \pm 3.39$ \\
\hline Risk level & Risk & Risk \\
\hline
\end{tabular}

Note: Mean \pm standard deviation for four subjects.

Table 4 OCRA index values for the two-handed insertion tasks

\begin{tabular}{|c|c|c|c|c|}
\hline & \multicolumn{2}{|c|}{ Human subject experiment } & \multicolumn{2}{|c|}{ DHMs } \\
\hline & $L U L$ & $R U L$ & $L U L$ & $R U L$ \\
\hline NTC & 1 & 3 & 3 & 2 \\
\hline $\mathrm{CT}$ & $4.14 \pm 0.14$ & $4.14 \pm 0.14$ & $4.35 \pm 0.13$ & $4.35 \pm 0.13$ \\
\hline $\mathrm{F}$ & $14.51 \pm 0.46$ & $43.53 \pm 1.39$ & $13.80 \pm 0.41$ & $41.41 \pm 1.23$ \\
\hline $\mathrm{D}$ & $0.41 \pm 0.01$ & $0.41 \pm 0.01$ & $0.44 \pm 0.01$ & $0.44 \pm 0.01$ \\
\hline$A T A$ & 6 & 18 & 6 & 18 \\
\hline $\mathrm{CF}$ & 30 & 30 & 30 & 30 \\
\hline FoM & 1 & $0.57 \pm 0.15$ & 1 & $0.57 \pm 0.15$ \\
\hline PoM & $0.63 \pm 0.25$ & $0.53 \pm 0.05$ & $0.63 \pm 0.25$ & $0.55 \pm 0.10$ \\
\hline ReM & 0.7 & 0.7 & 0.7 & 0.7 \\
\hline AdM & 1 & 1 & 1 & 1 \\
\hline$R P A$ & $5.41 \pm 2.10$ & $2.60 \pm 0.73$ & $5.70 \pm 2.23$ & $2.89 \pm 1.01$ \\
\hline DuM & 1 & 1 & 1 & 1 \\
\hline $\mathrm{RcM}$ & 1 & 1 & 1 & 1 \\
\hline$R T A$ & $5.41 \pm 2.10$ & $2.60 \pm 0.73$ & $5.70 \pm 2.23$ & $2.89 \pm 1.01$ \\
\hline$O C R A$ & $1.21 \pm 0.34$ & $7.46 \pm 2.62$ & $1.15 \pm 0.32$ & $6.93 \pm 2.78$ \\
\hline Risk level & No risk & Risk & No risk & Risk \\
\hline
\end{tabular}

Note: Mean \pm standard deviation for four subjects. 
Table 5 OCRA index values for the insertion tasks with a tool

\begin{tabular}{|c|c|c|c|c|}
\hline & \multicolumn{2}{|c|}{ Human subject experiment } & \multicolumn{2}{|c|}{ DHMs } \\
\hline & $L U L$ & $R U L$ & $L U L$ & $R U L$ \\
\hline NTC & 1 & 3 & 3 & 2 \\
\hline $\mathrm{CT}$ & $3.99 \pm 0.37$ & $3.99 \pm 0.37$ & $4.14 \pm 0.35$ & $4.14 \pm 0.35$ \\
\hline $\mathrm{F}$ & $30.28 \pm 2.88$ & $30.28 \pm 2.88$ & $29.17 \pm 2.56$ & $29.17 \pm 2.56$ \\
\hline $\mathrm{D}$ & $0.40 \pm 0.04$ & $0.40 \pm 0.04$ & $0.41 \pm 0.03$ & $0.41 \pm 0.03$ \\
\hline$A T A$ & 12 & 12 & 12 & 12 \\
\hline $\mathrm{CF}$ & 30 & 30 & 30 & 30 \\
\hline FoM & 1 & $0.87 \pm 0.14$ & 1 & $0.87 \pm 0.14$ \\
\hline PoM & $0.61 \pm 0.16$ & $0.52 \pm 0.04$ & $0.61 \pm 0.16$ & $0.51 \pm 0.03$ \\
\hline ReM & 0.7 & 0.7 & 0.7 & 0.7 \\
\hline AdM & 1 & 1 & 1 & 1 \\
\hline$R P A$ & $5.12 \pm 1.43$ & $3.76 \pm 0.74$ & $5.30 \pm 1.44$ & $3.82 \pm 0.61$ \\
\hline DuM & 1 & 1 & 1 & 1 \\
\hline $\mathrm{RcM}$ & 1 & 1 & 1 & 1 \\
\hline$R T A$ & $5.12 \pm 1.43$ & $3.76 \pm 0.74$ & $5.30 \pm 1.44$ & $3.82 \pm 0.61$ \\
\hline$O C R A$ & $2.49 \pm 0.61$ & $3.30 \pm 0.67$ & $2.40 \pm 0.57$ & $3.23 \pm 0.61$ \\
\hline Risk level & Very low risk & Very low risk & Very low risk & Very low risk \\
\hline
\end{tabular}

Note: Mean \pm standard deviation for all subjects.

\section{Discussion}

Tables 3 to 5 show that the OCRA assessments for the experimental and simulated insertion tasks were consistent with each other.

The results also show that the simulated torques were compatible with human performance capabilities. This is particularly important, since common DHMs may compute joint torques and/or working postures that are sometimes not compatible with human performance capabilities, which can lead to erroneous ergonomic assessments (Lämkull et al., 2009; Savin, 2011).

Although we obtained similar trajectories and speed profiles in the experiments and in the simulations, the differences were more noticeable for small subjects (see Figure 10). This could be due to the fact that the horizontal distances (distances between the subjects and the insert sockets, or the ranges between the extreme insert sockets) were not adjusted according to the subjects' sizes [instead the heights of the table were set to $90 \%$ of the elbow-ground height, in accordance with European standards for a standing work activities which require normal visions and precisions (European standard EN ISO 14738:2008, 2008)]. 


\section{Conclusions and future works}

In this paper, we introduced dynamic DHMs which were controlled in force and acceleration. We used the DHMs to simulate an experimental insert fitting tasks in quasi-real-time, and we used the simulated postures, times and exertions to calculate OCRA index-based ergonomic assessments. Given limited information on the scenarios (typically initial and final operator-positions and clipping forces), the simulated ergonomic assessments were still in the same risk levels as OCRA assessments for corresponding experimental results. In addition, the simulated trajectories were similar to the experimental trajectories. These encouraging results show that our DHMs could be used to overcome some of the limitations of common DHMs.

For the simulations, we explicitly specified the types of grasps (palmar, pinch, full-handed) and the orientations of the objects in the subjects' hands. Based on the final orientations (the objects were attached to the subjects' hands). In the future, in order to generalise the DHMs, prehension functions need to be added to our kinematic model. To avoid excessively increasing the complexity of our kinematic model, with 20 segments and 28 additional dof per hand (Miyata et al., 2005), we need to replace the wrist model with an end-effector with characteristics (number of joints, types, rotational and translational ranges) that can be used to model observed dof for each type of grasp (Miller et al., 2003). As a result, the end effector will have more dof in pinch mode than in full-handed grasp mode.

In this article, we used several controller parameters. To improve the controller, the tasks weights could be automatically modified to reduce complex tuning (Salini, 2012). In addition, to take account of obstacles in the workstation, path-planning (Escande, 2008; Toussaint et al., 2007; Lamarche, 2009), obstacle avoidance and auto-collision (Stasse et al., 2008) features could also be added.

In the long term, the contributions in this paper, and in future work, will result in the creation of an ergonomic evaluation software tool that can be integrated into CAD software tools, which consists of dynamic DHMs with human-like behaviours and characteristics.

\section{References}

Abe, Y., Silva, M.D. and Popovic, J. (2007) 'Multiobjective control with frictional contacts', in Proceedings ACM SIGGRAPH/EG Symposium on Computer Animation, Aire-la-Ville, Switzerland, pp.249-258.

AFNOR (2005) NF EN 1005-4 - sécurité des machines - performance physique humaine - partie 4 , La Plaine St-Denis, AFNOR.

AFNOR (2007) NF EN 1005-5 - sécurité des machines - performance physique humaine - partie 5: appréciation du risque relatif à la manutention répétitive à fréquence élevée, La Plaine St-Denis, AFNOR.

AFNOR (2010) NF EN ISO 12100: Sécurité des machines - principes généraux de conception - appréciation du risque et réduction du risque, La Plaine St-Denis, AFNOR.

Annarumma, M., Pappalardo, M. and Naddeo, A. (2008) 'Methodology development of human task simulation as PLM solution related to OCRA ergonomic analysis', in Computer-Aided Innovation (CAI) - IFIP 20th World Computer Congress, Proceedings of the Second Topical Session on Computer-Aided Innovation, Milano, Italy, pp.19-29. 
Arndt, F. (2006) 'The digital factory planning and simulation of production in automotive industry', Informatics in Control, Automation and Robotics I, pp.27-29.

Askew, L.J., An, K.N., Morrey, B.F. and Chao, E.Y. (1981) 'Functional evaluation of the elbow. Normal motion requirements and strength determinations', Orthop. Trans., pp.5-304.

Badler, N. (1997) 'Virtual humans for animation, ergonomics, and simulation', in Proceedings of the IEEE Workshop on Non-rigid and Articulates Motion, pp.28-36.

Badler, N., Phillips, C. and Webber, B. (1993) Simulating Humans: Computer Graphics, Animation, and Control, Oxford University Press, Oxford.

Berlin, C., Örtengren, B., Lämkull, D. and Hanson, L. (2009) 'Corporate-internal vs. national standard - a comparison study of two ergonomics evaluation procedures used in automotive manufacturing', International Journal of Industrial Ergonomics, Vol. 39, No. 6, pp.940-946.

Bernard, B. (1997) Musculoskeletal Disorders and Workplace Factors - A Critical Review of Epidemiologic Evidence for Work-Related Musculoskeletal Disorders of the Neck, Upper Extremity, and Low Back, NIOSH, CDC (Centers for Disease Control and Prevention).

Bretl, T. and Lall, S. (2008) 'Testing static equilibrium for legged robots', IEEE Transactions on Robotics, Vol. 24, No. 4, pp.794-807.

Bureau of Labor Statistics (2011) Non Fatal Occupational Injuries and Illnesses Requiring Days Away from Work, 2010, in US Department of Labor, Bureau of Labor Statistics, Washington, DC.

Center for Ergonomics (2004) Energy Expenditure Prediction Program, University of Michigan, College of Engineering, Ann Arbor, MI.

Chaffin, D. (1997) 'Development of computerized human static strength simulation model for job design', Human Factors and Ergonomics in Manufacturing, Vol. 7, No. 4, pp.305-322.

Chaffin, D. (2001) 'Digital human modeling for vehicle and workplace design', in $S A E$, Warrendale, PA.

Chedmail, P., Maille, B. and Ramstein, E. (2002) 'Etat de l'art sur l'accessibilité et l'étude de l'ergonomie en réalité virtuelle', Mécanique \& Industries, Vol. 3, pp.147-152.

Chen, J., Wang, R., Liu, L., Song, J. (2011) 'Clustering of trajectories based on Hausdorff distance', in International Conference on Electronics, Communications and Control (ICECC) pp.1940-1944.

Ciriello, V.M., Snook, S.H., Webster, B.S. and Dempsey, P. (2001) 'Psychophysical study of six hand movements', Ergonomics, Vol. 44, No. 10, pp.922-936.

Claudon, L., Daille-Lefèvre, B. and Marsot, J. (2006) 'La révolution du numérique: un atout pour concevoir des postes de travail plus sûrs', Hygiène et Sécurité du Travail - Note Documentaire ND 2282, Vol. 210, pp.5-13.

CNAM-TS (2012) TMS: développer des plans de prévention durables pour réduire la progression du risque.

Colette, C., Micaelli, A., Andriot, C. and Lemerle, P. (2007) 'Dynamic balance control of humanoids for multiple grasps and non coplanar frictional contacts', in 7th IEEE-RAS International Conference on Humanoid Robots, Pittsburgh, PA, pp.81-88.

Colette, C., Micaelli, A., Andriot, C. and Lemerle, P. (2008) 'Robust balance optimization control of humanoid robots with multiple non coplanar grasps and frictional contacts', in Proceedings of the IEEE International Conference on Robotics and Automation, Pasadena, USA, pp.3187-3193.

De Magistris, G., Micaelli, A., Andriot, C., Savin, J. and Marsot, J. (2011) 'Dynamic virtual manikin control design for the assessment of the workstation ergonomy', in 1st International Symposium on Digital Human Modeling, Lyon.

De Magistris, G., Micaelli, A., Evrard, P. and Savin, J. (2014) 'A human-like learning control for digital human models in a physics-based virtual environment', The Visual Computer, pp.1-18, DOI: 10.1007/s00371-014-0939-0. 
De Magistris, G., Micaelli, A., Evrard, P., Andriot, C., Savin, J., Gaudez, C. and Marsot, J. (2013a) 'Dynamic control of DHM for ergonomic assessments', International Journal of Industrial Ergonomics, Vol. 43, No. 2, pp.170-180.

De Magistris, G., Micaelli, A., Savin, J., Gaudez, C. and Marsot, J. (2013b) 'Dynamic digital human model for ergonomic assessment based on human-like behaviour and requiring a reduced set of data for a simulation', in 2nd International Digital Human Model Symposium, Ann Arbor, USA.

Dukic, T., Ronang, M. and Christmansson, M. (2007) 'Evaluation of ergonomics in a virtual manufacturing process', Journal of Engineering Design, Vol. 18, No. 2, pp.125-137.

Escande, A. (2008) Planification de points d'appui pour la génération de mouvements acycliques: application aux humanoïdes, $\mathrm{PhD}$ thesis, Université d'Evry-Val d'Esonne, France.

European Standard EN ISO 14738:2008 (2008) Safety of Machinery - Anthropometric Requirements for the Design of Workstations at Machinery, ISO.

European Union (2006) 'Directive on machinery - Directive 2006/42/EC of the European parliament and of the council of 17 may 2006 on machinery', Official Journal of the European Union.

Falck, A. and Rosenqvist, M. (2012) 'What are the obstacles and needs of proactive ergonomics measures at early product development stages? - An interview study in five Swedish companies', International Journal of Industrial Ergonomics, Vol. 42, No. 5, pp.406-415.

Fitts, P. (1954) 'The information capacity of the human motor system in controlling the amplitude of movement', Journal of Experimental Psychology, Vol. 47, No. 6, pp.381-391.

Flash, T. and Hogan, N. (1985) 'The coordination of arm movements: an experimentally confirmed mathematical model', Journal of Neuroscience, Vol. 5, No. 7, pp.1688-1703.

Fritzsche, L., Jerndrusch, R., Leidholdt, W., Bauer, S., Jäckel, T. and Pirger, A. (2011) 'Introducing ema (editor for manual work activities) - a new tool for enhancing accuracy and efficiency of human simulations', in V.G. Duffy (Éd.): Digital Production Planning, Digital Human Modeling, Lecture Notes in Computer Science, Vol. 6777, pp.272-281.

Gaudez, C. (2008) 'Upper limb musculo-skeletal disorders and insert fitting activity in automobile sector: impact on muscular stresses of fitting method and insert position on part', Computer Methods in Biomechanics and Biomedical Engineering, Vol. 11, Supplement 001, pp.101-102.

Gribble, P. and Ostry, D. (1999) 'Compensation for interaction torques during single and multi-joint limb movement', Journal of Neurophysiology, Vol. 82, No. 5, pp.2310-2326.

Haesen, B. (2009) 'Betterlift - introducing a semi-automaic exhaust manipulator to reduce a high absenteeism rate', Int. Assessment, Elimination and Substantial Reduction of Occupational Risks - European Agency for Safety and Health at Work (Eu-OSHA) pp.36-43.

Hanavan, E. (1964) 'A mathematical model of the human body', Wright-Patterson Air Force Base, Report No. AMRL-TR-102, pp.64-102.

Hogan, N. (1990) 'Mechanical impedance of single- and multi-articular systems', in J.M. Winters and S.L. Woo (Eds.): Multiple Muscle Systems: Biomechanics and Movement Organization, Springer-Verlag.

Hyman, R. (1953) 'Stimulus information as a determinant of reaction time', Journal of Experimental Psychology, Vol. 45, No. 3, pp.188-196.

Jayaram, U., Jayaram, S., Shaikh, I., Kim, Y. and Palmer, C. (2006) 'Introducing quantitative analysis methods into virtual environments for real-time and continuous ergonomic evaluations', Computers in Industry, Vol. 57, No. 3, pp.283-296.

Karu, O., Kansi, P. and Kouarinka, I. (1977) 'Correcting working postures in industry: a practical method for analysis', Applied Ergonomics, Vol. 8, No. 4, pp.199-201.

Kilbom, A. and Persson, J. (1987) 'Work technique and its consequences for musculoskeletal disorders', Ergonomics, Vol. 30, No. 2, pp.273-279. 
Kuo, C. and Wang, M. (2009) 'Motion generation from MTM semantics', Computers in Industry, Vol. 60, No. 5, pp.339-348.

Lackner, J. and Dizio, P. (1994) 'Rapid adaptation to coriolis force perturbations of arm trajectory', Journal of Neurophysiology, Vol. 72, No. 1, pp.299-313.

Lamarche, F. (2009) 'Topoplan: a topological path planner for real time human navigation under floor and ceiling constraints', Computer Graphics Forum, Vol. 28, No. 6, pp.649-658.

Lämkull, D., Hanson, L. and Ortengren, R. (2009) 'A comparative study of digital human modelling simulation results and their outcomes in reality: a case study within manual assembly of automobiles', International Journal of Industrial Ergonomics, Vol. 39, No. 2, pp.428-441.

Liu, M., Micaelli, A., Evrard, P., Escande, A. and Andriot, C. (2011) 'Interactive dynamics and balance of a virtual character during manipulation tasks', in IEEE International Conference on Robotics and Automation, Shanghai, China, pp.1676-1682.

MacAtamney, L. and Cortlett, E. (1993) 'Rula: a survey method for the investigation of work-related upper limb disorders', Applied Ergonomics, Vol. 24, No. 8, pp.91-99.

Malchaire, J. (2011) Guide: classification des méthodes d'évaluation et/ou de prévention des risques de TMS.

Mansour, D., Micaelli, A. and Lemerle, P. (2011) 'A computational approach for push recovery in case of multiple noncoplanar contacts', in International Conference on Intelligent Robots and Systems (IROS), pp.3213-3220.

Maynard, H., Stegemerten, G. and Schwab, J. (1948) Methods-time Measurement, McGraw Hill Book Company, New York.

Merlhiot, X. (2009) 'Extension of a time-stepping compatible contact determination method between rigid bodies to deformable models', in Proceedings of the Multibody Dynamics ECCOMAS Thematic Conference.

Miller, A., Knoop, S., Christensen, H. and Allen, P. (2003) 'Automatic grasp planning using shape primitives', in IEEE International Conference on Robotics and Automation, Vol. 2, pp.1824-1829.

Miyata, N., Kouki, M., Mochimaru, M., Kawachi, K. and Kurihara, T. (2005) 'Hand link modelling and motion generation from motion capture data based on 3d joint kinematics', in Proceedings SAE International Iowa.

Monnier, G. (2004) Simulation de mouvements humains complexes et prédiction de l'inconfort associé - application à l'évaluation ergonomique du bouclage de la ceinture de sécurité, $\mathrm{PhD}$ thesis, Institut National des Sciences Appliquées de Lyon.

Morasso, P. (1981) 'Spatial control of arm movements', Experimental Brain Research, Vol. 42, No. 2, pp.223-227.

Morasso, P. and Mussa-Ivaldi, F. (1982) 'Trajectory formation and handwriting: a computational model', Biological Cybernetics, Vol. 45, No. 2, pp.131-142.

Morrisey, M. (1998) 'Human-centric design', Mechanical Engineering, Vol. 120, No. 7, pp.60-62.

NIOSH (1991) Work Practice Guide for Manual Lifting, Technical report 81-122, Department of Health and Human service, San Francisco, California.

NST-n168 (1998) Ergonomie des outils à main - problématique et état de l'art, Note scientifique et technique de l'INRS.

Occhipinti, E. (1998) 'OCRA, a concise index for the assessment of exposure to repetitive movements of the upper limbs', Ergonomics, Vol. 41, No. 9, pp.1290-1311.

Porter, J.M., Case, K., Marshall, R., Gyi, D. and Sims, R. (2004) 'Beyond Jack and Jill: designing for individuals using Hadrian', International Journal of Industrial Ergonomics, Vol. 33, No. 3, pp.249-264. 
Pouliquen, M. (2006) Proposition d'un modèle de main pour la simulation des interactions hommemachine dans un environnent virtuel: application à la prévention des accidents aux mains, Vol. NTS 263, p.268.

Pratt, J., Torres, A., Dilworth, P. and Pratt, G. (1996) 'Virtual actuator control', in IEEE International Conference on Intelligent Robots and Systems, pp.1219-1226.

Rice, S. (2004) 'Boeing human modeling system. Working postures and movements', in N.J. Delleman, C.M. Haslegrave and D.B. Chaffin (Eds.): Tools for Evaluation and Engineering, pp.462-465, CRC Press.

Salini, J. (2012) Dynamic Control for the Task/posture Coordination of Humanoids: Toward Synthesis of Complex Activities, $\mathrm{PhD}$ thesis, University of Pierre and Marie Curie.

Savin, J. (2011) 'Digital human manikins for work-task ergonomic assessment: which degree of confidence and using constraints?', Proceedings of the Institution of Mechanical Engineers, Part B: Journal of Engineering Manufacture, Vol. 225, pp.1401-1409.

Schaub, K., Caragnano, G., Britzke, B. and Bruder, R. (2012) The European Assembly Worksheet, Theoretical Issues in Ergonomics Science.

Schaub, K., Landau, K., Menges, R. and Grossmann, K. (1997) 'A computer-aided tool for ergonomic workplace design and preventive health care', Human Factors and Ergonomics in Manufacturing, Vol. 7, No. 4, pp.269-304.

Schutter, J.D. (2010) 'Invariant description of rigid body motion trajectories', ASME Journal of Mechanisms and Robotics, Vol. 2, No. 1, p.9.

Seidl, A. (2004) 'The ramsis human simulation tool. working postures and movements', in N.J. Delleman, C.M. Haslegrave and D.B. Chaffin (Eds.): Tools for Evaluation and Engineering, pp.445-450, CRC Press.

Shahrokhi, M. and Bernard, A. (2009) 'A framework to develop an analysis agent for evaluating human performance in manufacturing systems', CIRP Journal of Manufacturing Science and Technology, Vol. 2, No. 1, pp.55-60.

Sjogaard, G., Sejersted, O.M., Winkel, J., Smolander, J., Jorgensen, K. and Westgaard, R. (1995) 'Exposure assessment and mechanisms of pathogenesis in work-related musculoskeletal disorders: Significant aspects in the documentation of risk factors', in O. Svane and C. Johansen (Eds.): Work and Health. Scientific Basis of Progress in the Working Environment.

Stasse, O., Escande, A., Mansard, N., Miossec, S., Evrard, P. and Kheddar, A. (2008) 'Real time selfcollision avoidance task on hrp-2 humanoid robot', in IEEE International Conference on Robotics and Automation, Pasadena, USA, pp.3200-3205.

Todorov, E. and Jordan, M. (1998) 'Smoothness maximization along a predefined path accurately predicts the speed profiles of complex arm movements', Journal of Neurophysiology, Vol. 80, No. 2, pp.697-714.

Toussaint, M., Gienger, M. and Goerick, C. (2007) 'Optimization of sequential attractor-based movement for compact behaviour generation', in IEEE International Conference on Humanoid Robots.

Uno, Y., Kawato, M. and Suzuki, R. (1989) 'Formation and control of optimal trajectory in human multijoint arm movement: minimum torque-change model', Biological Cybernetics, Vol. 61, No. 1, pp.89-101.

Urbatic Concept France (2007) 'Une approche innovante de l'ergonomie', Ergonoma Journal, Vol. 48, No. 7, pp.22-23.

Vignes, R. (2004) Modeling Muscle Fatigue in Digital Humans, Center for Computer-Aided Design, The University of IOWA, Tech. rep.

VSR Research Group (2004) Technical Report for Project Virtual Soldier Research, Center for Computer-Aided Design, The University of IOWA, Tech. rep. 
Wang, X. (2008) Contribution à la simulation du mouvement humain en vue d'applications en ergonomie, Mémoire de HDR, Université Claude Bernard - Lyon I, Report No. 5-2008.

Yoshizaki,W., Suguira, Y., Chiou, A., Hashimoto, S., Inami, M., Igarashi, T., Akazawa, Y., Kawachi, K., Kagami, S. and Mochimaru, M. (2011) 'An actuated physical puppet as an input device for controlling a digital manikin', in Proceedings of the SIGCHI Conference on Human Factors in Computing Systems, New York, USA, pp.637-646.

Zhang, B., Horvath, I., Molenbroek, J. and Snijders, C. (2010) 'Using artificial neural networks for human body posture prediction', International Journal of Industrial Ergonomics, Vol. 40, No. 4, pp.414-424.

Zhang, X., Nussbaum, M. and Chaffin, D. (2000) 'Back lift versus leg lift: an index and visualization of dynamic lifting strategies', Journal of Biomechanics, Vol. 33, No. 6, pp.777-782. 